Supporting Information

\title{
Synthesis of Au and Pt Hollow Capsules with Single Holes via Pickering Emulsion Strategy
}

Jie Xu, ${ }^{\dagger}$ Aijing Ma,${ }^{\dagger}$ Zhemi Xu, ${ }^{\dagger}$ Xiaokong Liu,${ }^{\dagger}$ Dewei Chu, ${ }^{\dagger}$ and Haolan $\mathrm{Xu}^{*},{ }^{\dagger}$

${ }^{\dagger}$ Ian Wark Research Institute, University of South Australia, Mawson Lakes Campus, SA 5095, Australia.

\$ School of Materials Science and Engineering, University of New South Wales, Sydney, NSW 2052, Australian.

\section{Synthesis of cubic and octahedral $\mathrm{Cu}_{2} \mathrm{O}$ particles}

Cubic $\mathrm{Cu}_{2} \mathrm{O}$ particles: $0.5 \mathrm{~g}$ of $\mathrm{Cu}\left(\mathrm{CH}_{3} \mathrm{COO}\right)_{2} \cdot \mathrm{H}_{2} \mathrm{O}$ was dissolved in $50 \mathrm{~mL}$ of $\mathrm{H}_{2} \mathrm{O}$ followed by heating up to $70{ }^{\circ} \mathrm{C}$. Then, $2.5 \mathrm{~mL}$ of $\mathrm{NaOH}$ solution $(6 \mathrm{M})$ was added into the solution. After blue suspension of $\mathrm{Cu}(\mathrm{OH})_{2}$ was produced, $0.1 \mathrm{~g}$ of glucose was added into the suspension. The mixture solution was kept stirring $(450 \mathrm{rpm})$ for $60 \mathrm{~min}$ at temperature of $70{ }^{\circ} \mathrm{C}$. The red precipitates were collected and washed with water and ethanol for several times.

Octahedral $\mathrm{Cu}_{2} \mathrm{O}$ particles: $0.3 \mathrm{~g}$ of $\mathrm{Cu}\left(\mathrm{CH}_{3} \mathrm{COO}\right)_{2} \cdot \mathrm{H}_{2} \mathrm{O}$ was dissolved into $5 \mathrm{~mL}$ of water. Then, $3 \mathrm{~mL}$ of $\mathrm{NaOH}$ aqueous solution $(3 \mathrm{M})$ was added into the solution under constant stirring. Blue $\mathrm{Cu}(\mathrm{OH})_{2}$ was produced. The suspension was kept stirring at $500 \mathrm{rpm}$ for $10 \mathrm{~min}$. Then $0.06 \mathrm{~g}$ of glucose was added into the suspension. The resulting suspension was stirred for another $10 \mathrm{~min}$. Then, the mixture solution was placed in the water bath at temperature of $71{ }^{\circ} \mathrm{C}$ for $5 \mathrm{~min}$ and was mildly stirred at $200 \mathrm{rpm}$. The obtained samples were centrifuged and washed with water and ethanol for three times. 

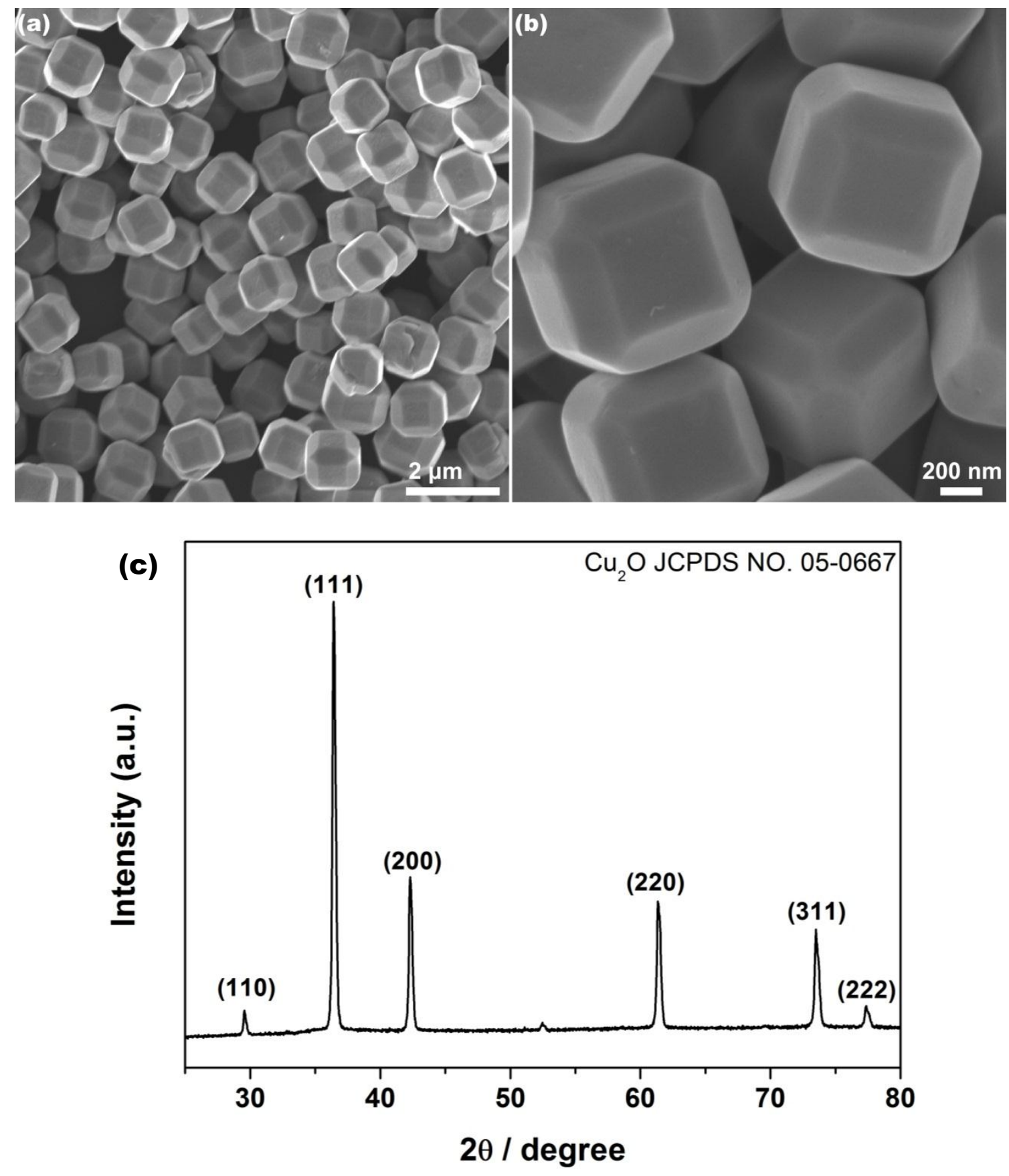

Figure S1. (a, b) SEM images of the emulsifier $\mathrm{Cu}_{2} \mathrm{O}$ MFPs; (c) XRD pattern of the $\mathrm{Cu}_{2} \mathrm{O}$ MFPs. 


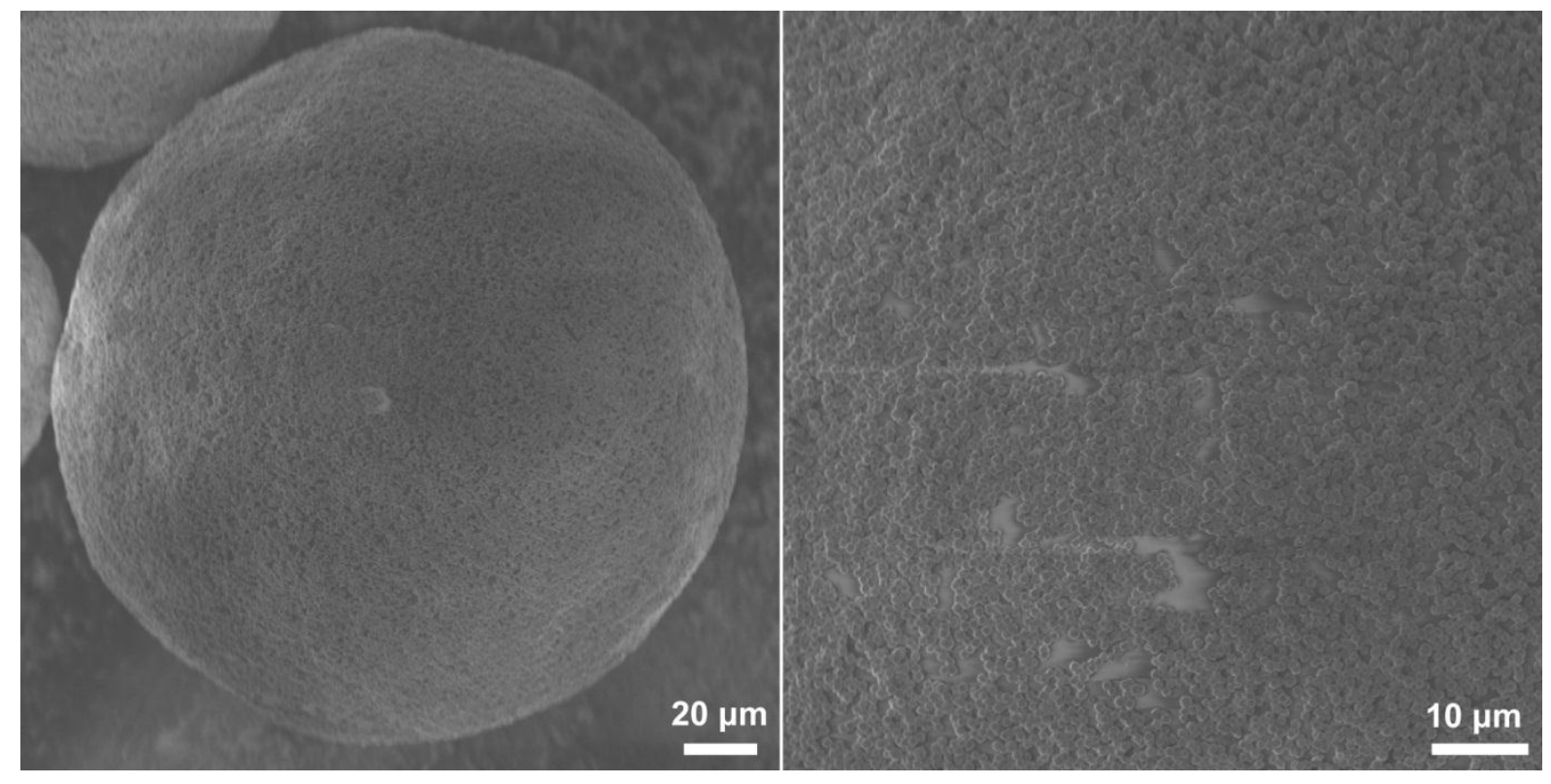

Figure S2. SEM images of the solidified $\mathrm{Cu}_{2} \mathrm{O}$ MFPs stabilized Pickering emulsions. 
(a)

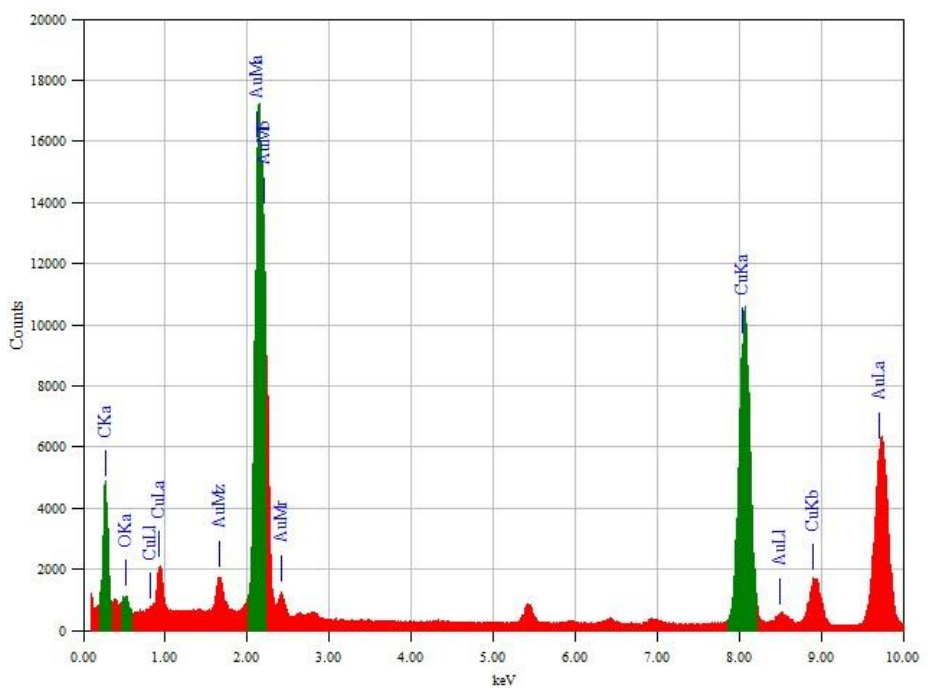

(b)

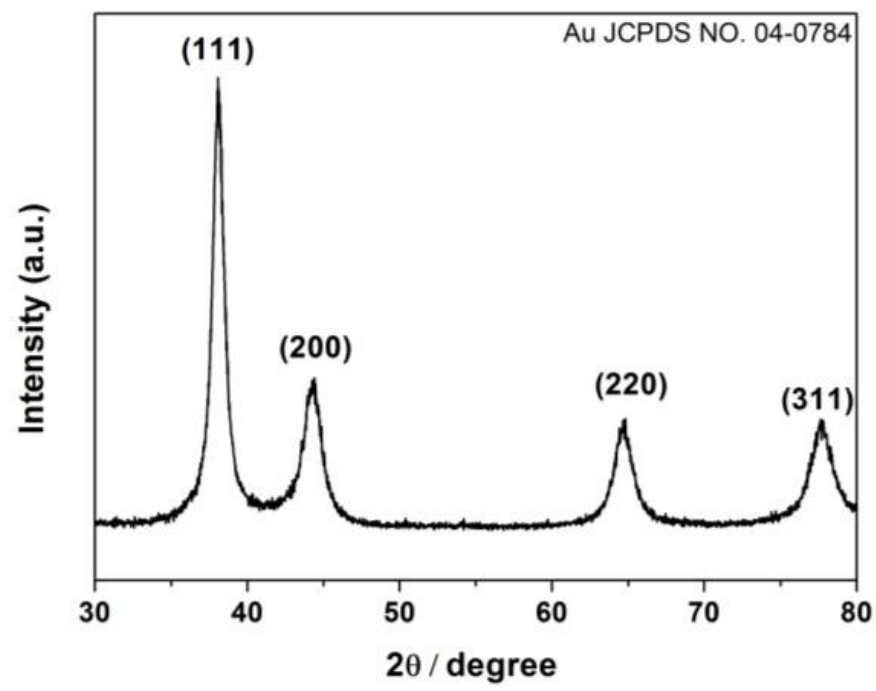

(c)

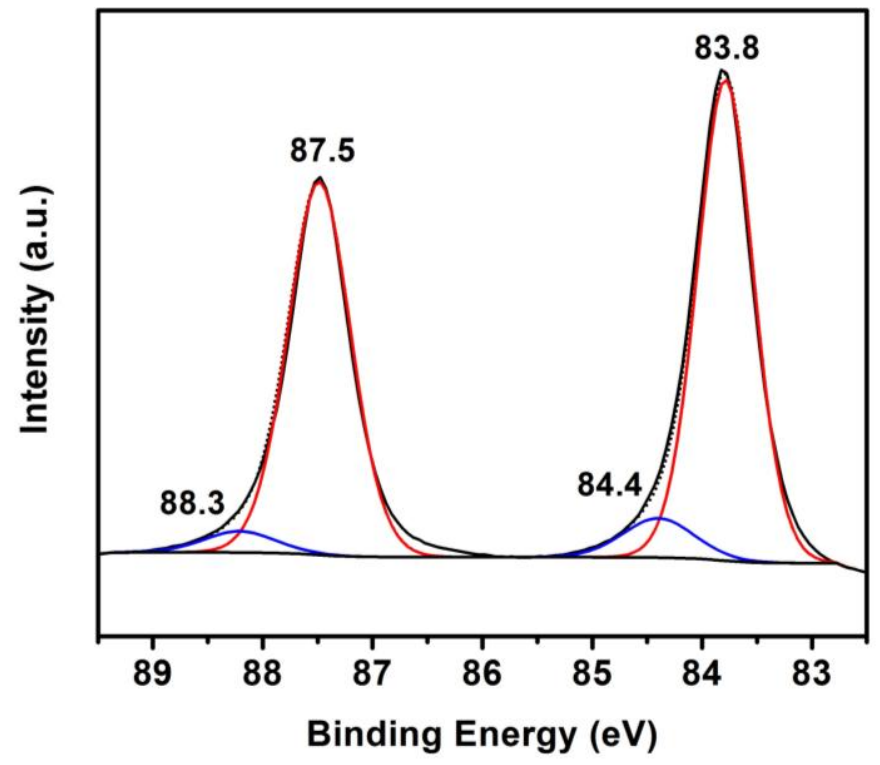

Figure S3. (a) EDX spectrum of an open-mouthed hollow capsule shown in Fig. 2d. The main element is $\mathrm{Au}$. The element of $\mathrm{C}$ and $\mathrm{Cu}$ arise from the carbon coated copper grid. (b) XRD pattern and (c) XPS spectrum of the open-mouthed hollow capsules. 

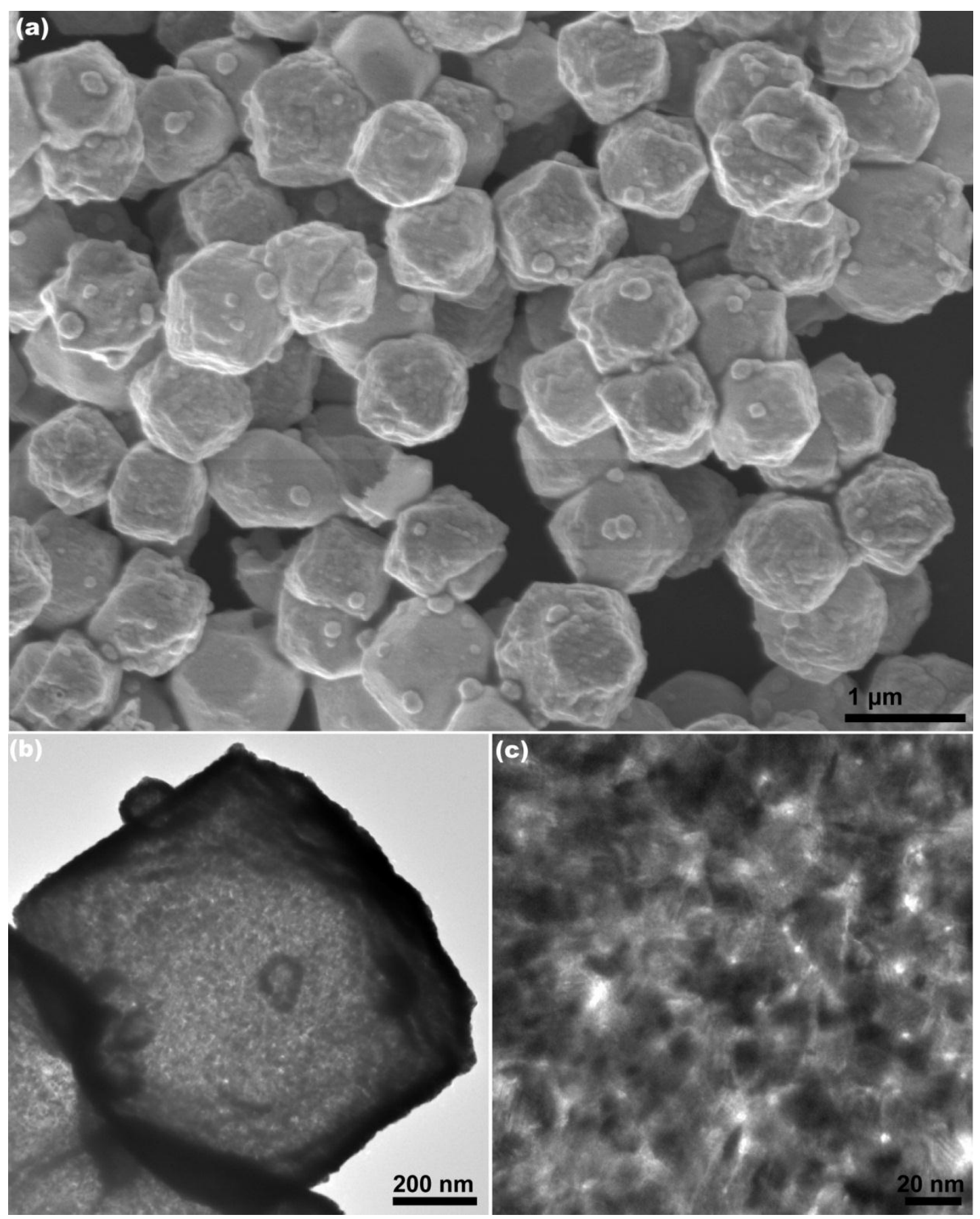

Figure S4. SEM (a) and TEM (b, c) images of the intact Au hollow capsules prepared via direct galvanic reaction in bulk solution without the presence of Pickering emulsions. 


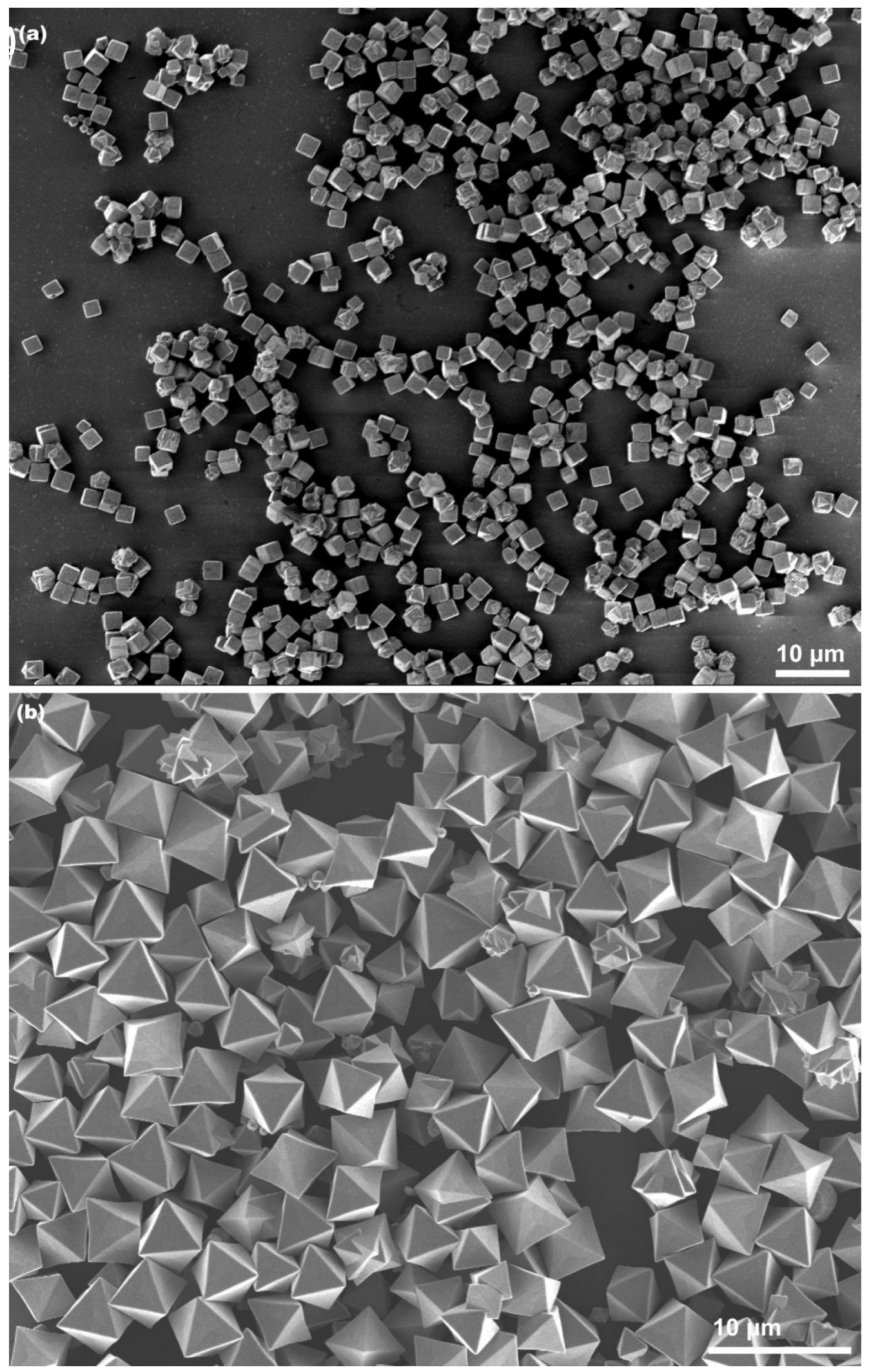

Figure S5. SEM images of $\mathrm{Cu}_{2} \mathrm{O}$ cubic (a) and octahedral (b) particles. 

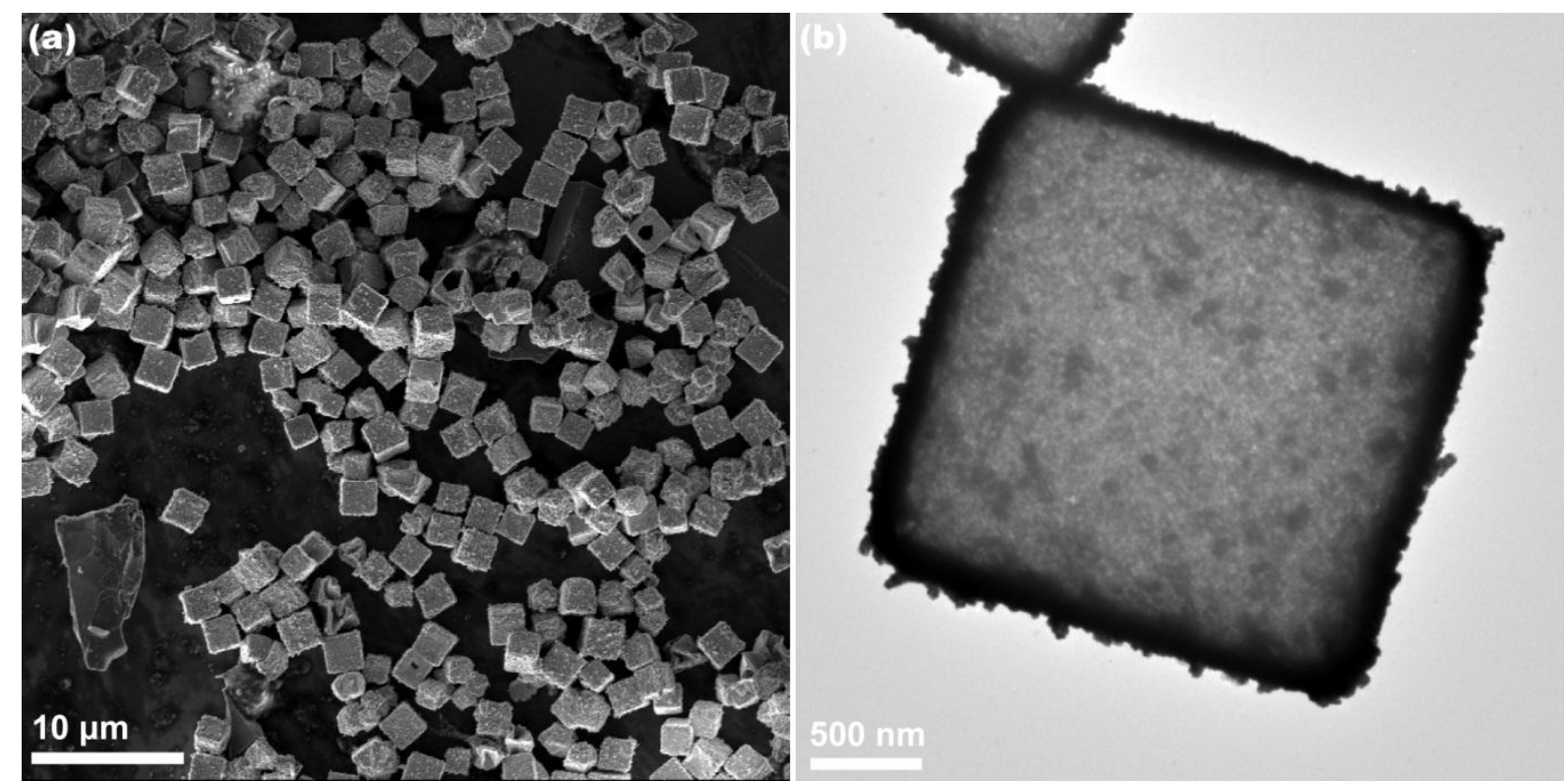

Figure S6. SEM (a) and TEM (b) images of the intact Au hollow cubes prepared via direct galvanic reaction in bulk solution without the presence of Pickering emulsions. 

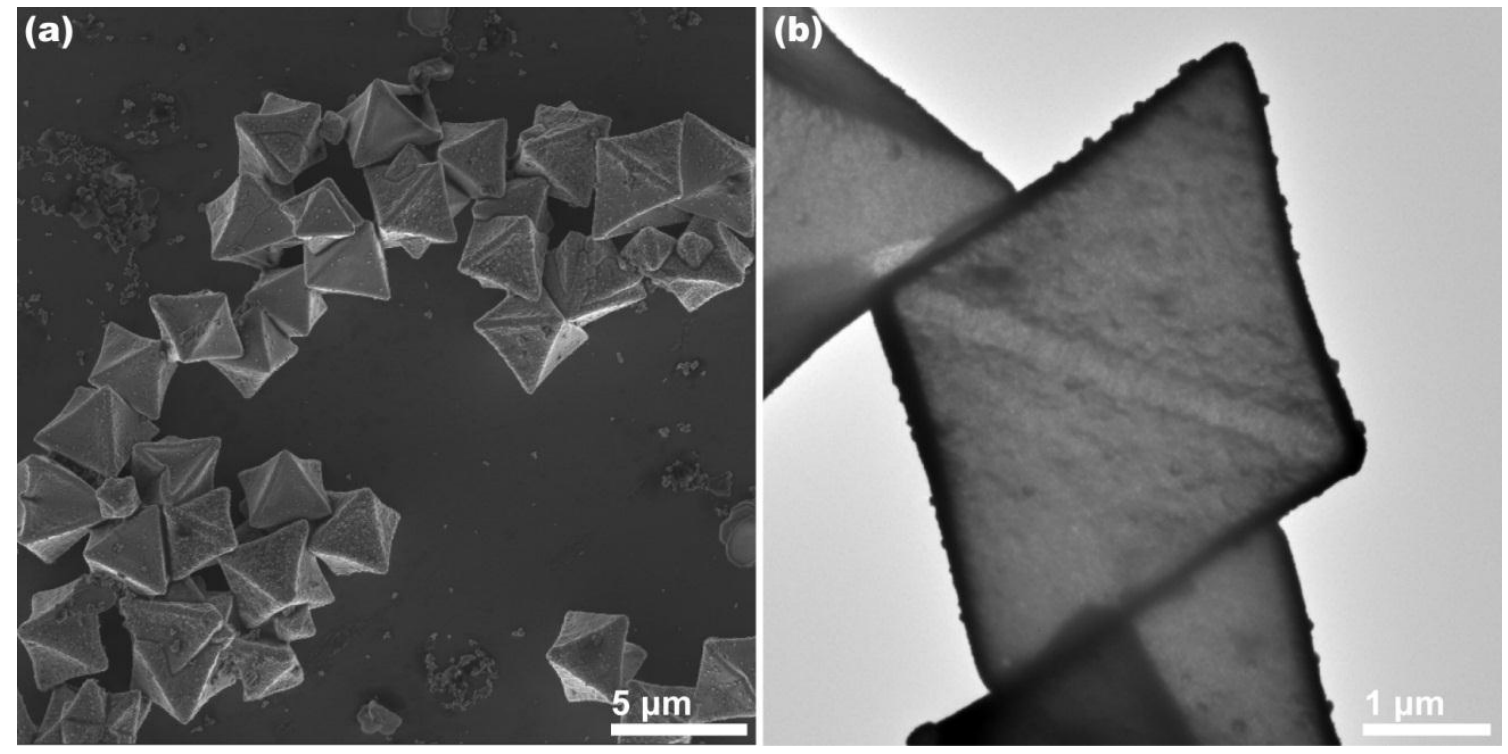

Figure S7. SEM (a) and TEM (b) images of the intact Au hollow octahedra prepared via direct galvanic reaction in bulk solution without the presence of Pickering emulsions. 


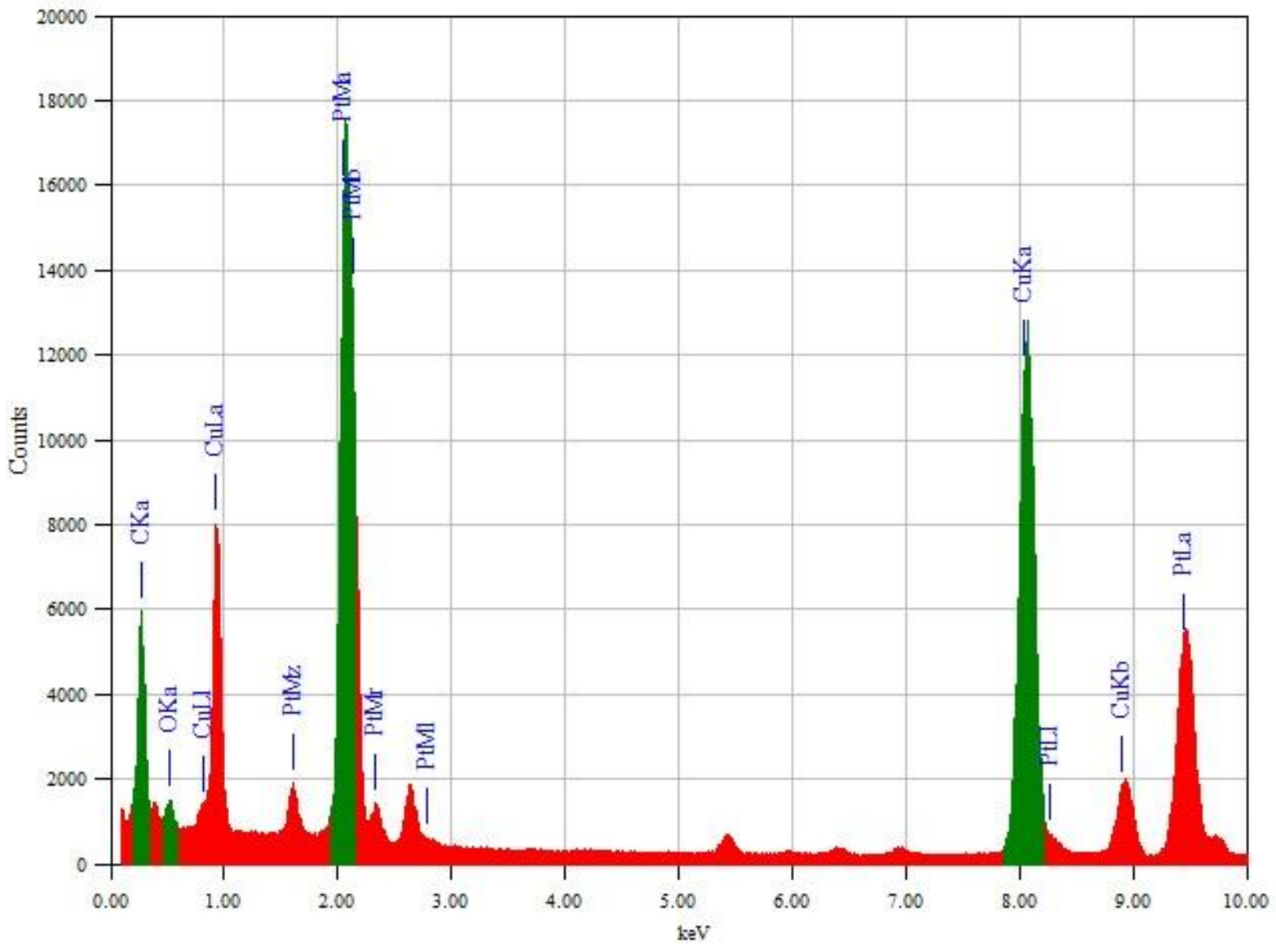

Figure S8. EDX spectrum of open-mouthed Pt hollow capsules. The main element is Pt. The element of $\mathrm{C}$ and $\mathrm{Cu}$ arise from the carbon coated copper grid. 

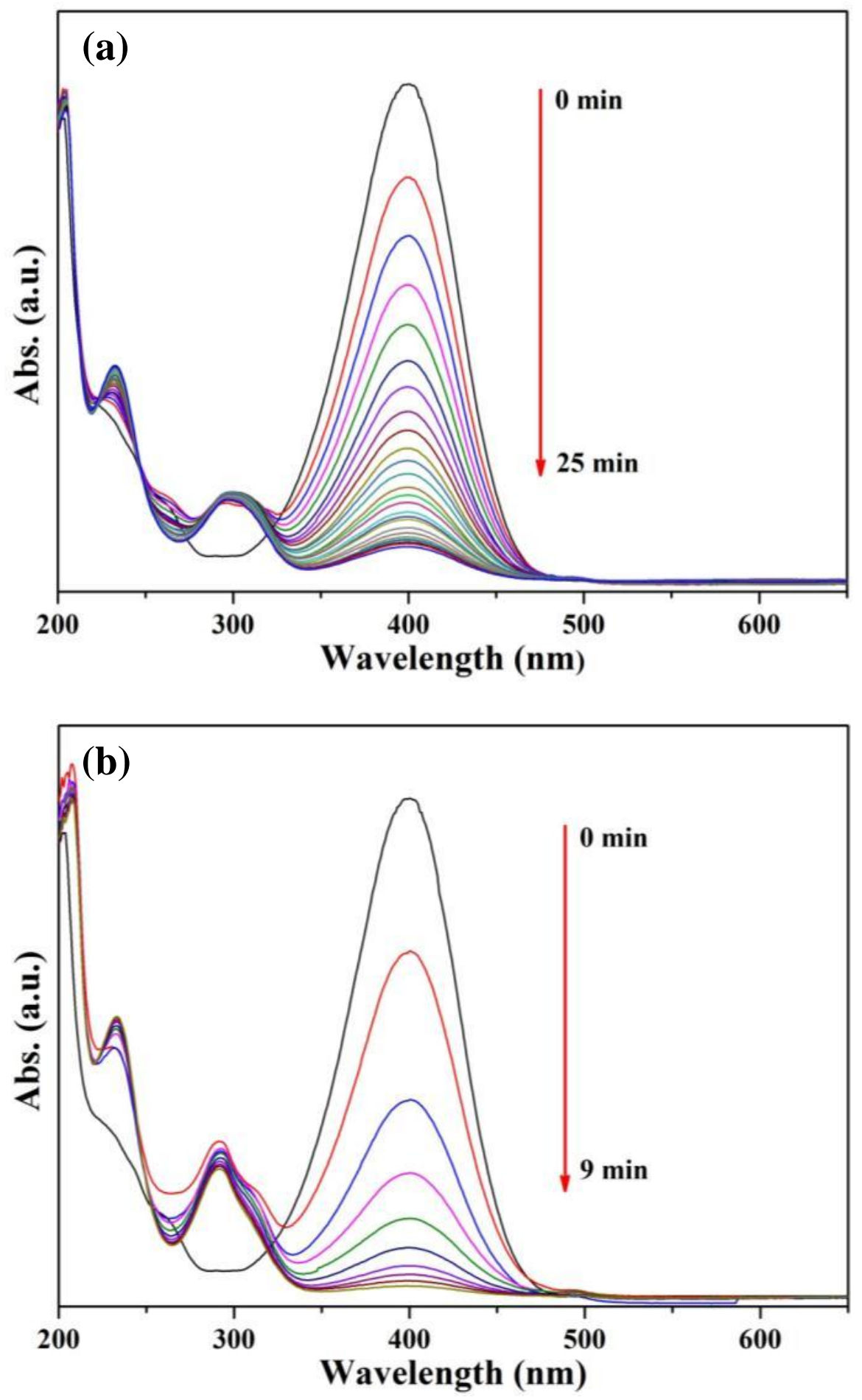

Figure S9. Time-dependent UV-vis spectra of the reaction solution catalysed by (a) intact $\mathrm{Au}$ hollow capsules, (b) open-mouthed Au hollow capsules. 